\title{
Breeding Behaviour of the
}

\section{FATHEAD MINNOW}

\author{
by VICKY McMILLAN*
}

The fathead minnow (Pimeplates promelas Rafinesque), a member of the Cyprinidae or Minnow Family, is common in southern Saskatchewan. Important as a bait and forage fish, it has been introduced into much of North America and presently occurs throughout southern Canada, the entire United States and northern Mexico. Fatheads have been of considerable value in studying aquatic pollution and evaluating the biological effects of material from the moon. Surprisingly, however, they have been little studied for their own sake.

For two years (spring, 1970-72) I analyzed the breeding behaviour of the fathead minnow, under the supervision of Dr. R. J. F. Smith, for a M.Sc. degree from the University of Saskatchewan. Observations were conducted in laboratory aquaria, in an artificial pond, and at Blackstrap Lake, Saskatchewan, where fatheads occurred in great numbers. This research elucidated many fascinating habits of the species - habits easily seen by anyone with a little patience and curiosity. This article is intended as an introduction to the fathead minnow for residents of the Prairie Provinces and, hopefully, as a stimulus for additional observations of the fish.

The fathead minnow is a robust, dusky bronze fish reaching a maximum total length of $90-100 \mathrm{~mm}(3-1 / 2-4$ inches). During the breeding season, males differ from females in four major respects. First, true to their name, they have large heads - looking much like "goldfish with heavy black socks pulled over their heads," as biologist R. B. Miller once described them (Fig. 1). Males also have three

\footnotetext{
* No. 206, 211 Ash Street,
}

New Westminster, B.C.
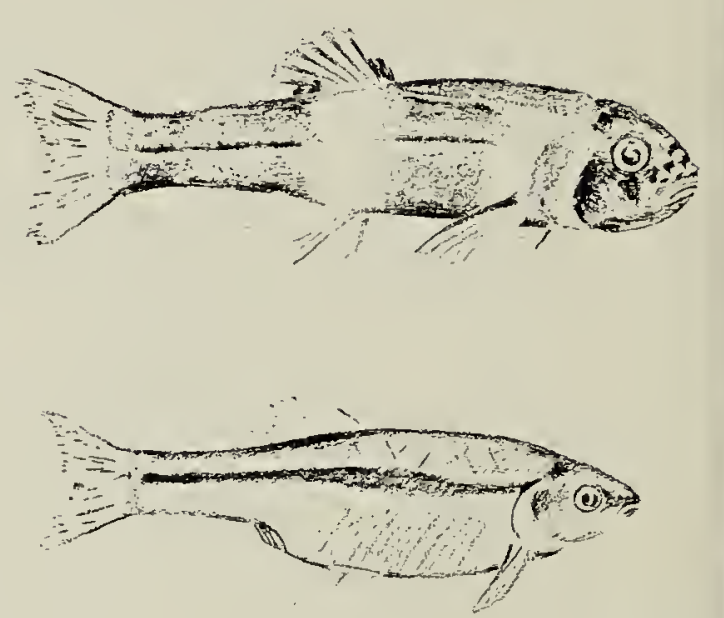

Fig. 1. Male (top) and female fa. McMill le fathead mi nows in breeding condition. Note th black head, tubercles, dorsal pad an banding of the male: and the pal colouration, smaller head and distende condition of the ripe female.

horizontal rows of tubercles on the snouts, plus tubercles on the pector fins and frequently on the chin (Fi 2 and cover). The tubercles a seasonal growths of the epidermis an appear as horny, conical projection In various patterns they occur in oth species of minnows, and much interc has been aroused concerning the behavioural roles.

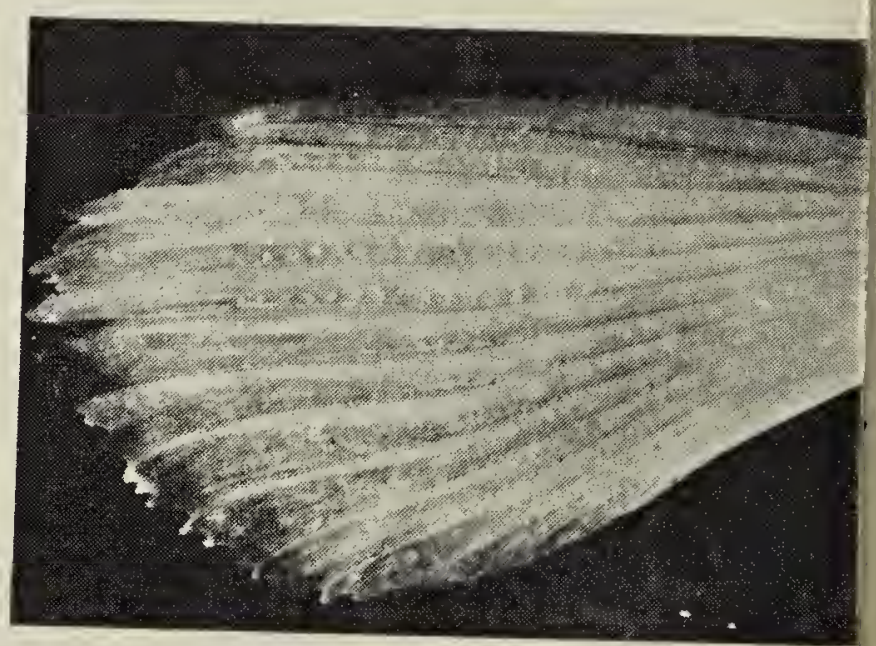

V. McMill:

Fig. 2. Upper surface of right pectoral fin a preserved breeding male fathead mir now. Tubercles, used in spawnin behaviour, can be seen along four of th anterior rays. 


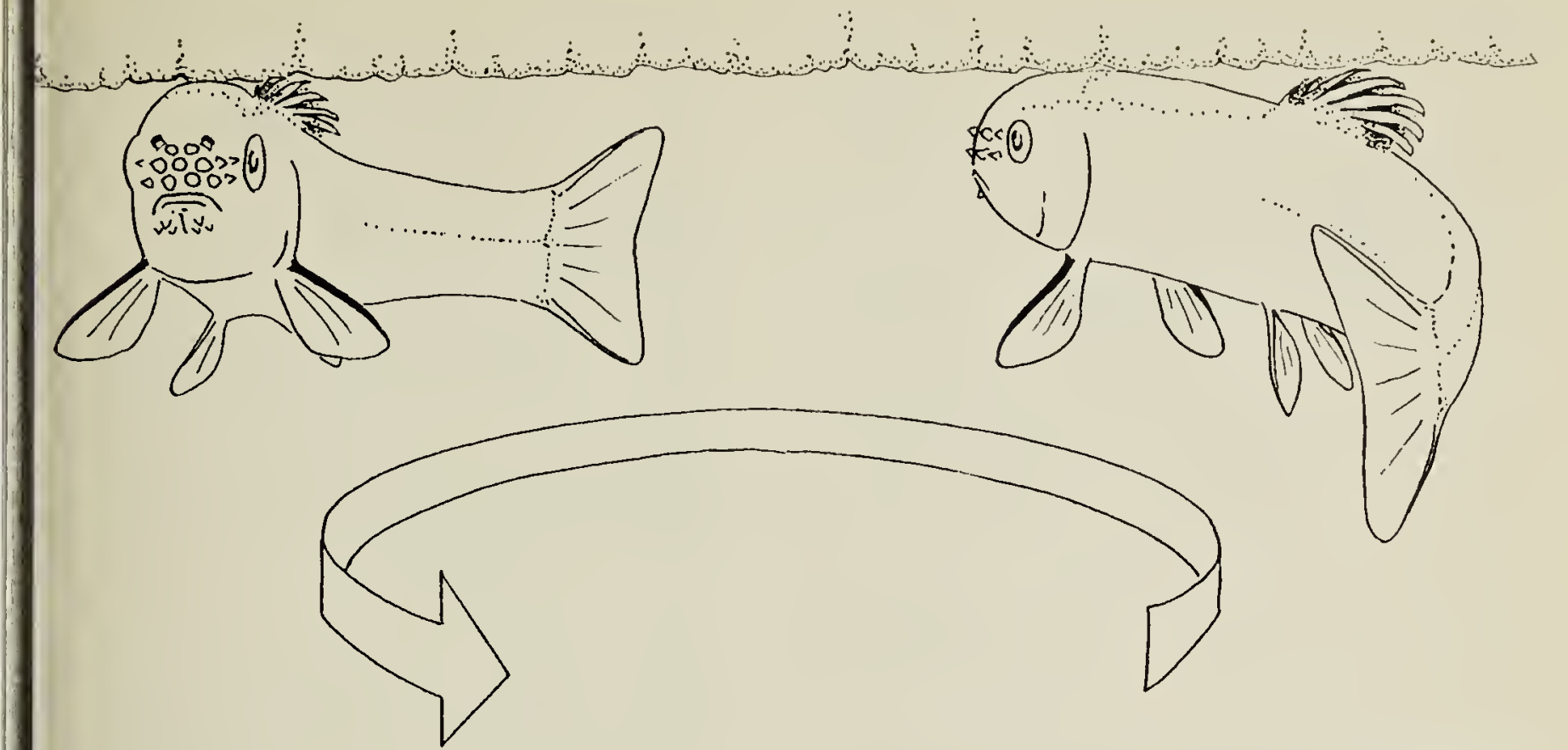

B. McMillan

ig. 3. Circling. Moving in a circular path, a breeding male brushes his dorsal pad across the underside of his territorial object.

Thirdly, breeding males may be arked with alternating light and dark ertical stripes. This banding - which lay appear and disappear in seconds - is most notable in situations inolving aggression or sexual activity. Inder good field conditions, the conrasting pattern of breeding males hakes them easily distinguishable rom females.

Finally, males possess a striking "dorsal pad" - a soft, thick, gray ushion extending from the back of the head to the dorsal fin. The pad is present only during the spawning feason and seems to play a major role in reproduction.

At Blackstrap Lake in 1970 and 1971, fathead minnows began breeding by early June and continued at least until early August. Peak breeding occurred from early June to early July. With the onset of reproductive activity, males move into shallow water and choose individual territories beneath floating or submerged objects. These "territorial objects" may be almost anything opaque - from lily pads and old tires to rocks and pieces of wood. At Blackstrap Lake, many males defended territories in cavities beneath stones along the rocky shores near the causeway. In aquaria, an ideal territorial object - from the observer's point of view - is an 8-inch concrete block shaped like the letter
$C$. The males occupies the cavity of the block (the "inside" of the $C$ ), and his actions can be easily observed.

Fathead minnows show such remarkable tenacity in maintaining their territories that they can be easily caught by hand. After selecting a territorial object, a male stays in its immediate vicinity, spending most of his time within several inches of the object's undersurface - where eggs will eventually be deposited in his care. Often a male moves in a circular path below his object, brushing his dorsal pad across its undersurface (Fig. 3). This circling helps to clean the object of algae and other debris and may perform other functions, such

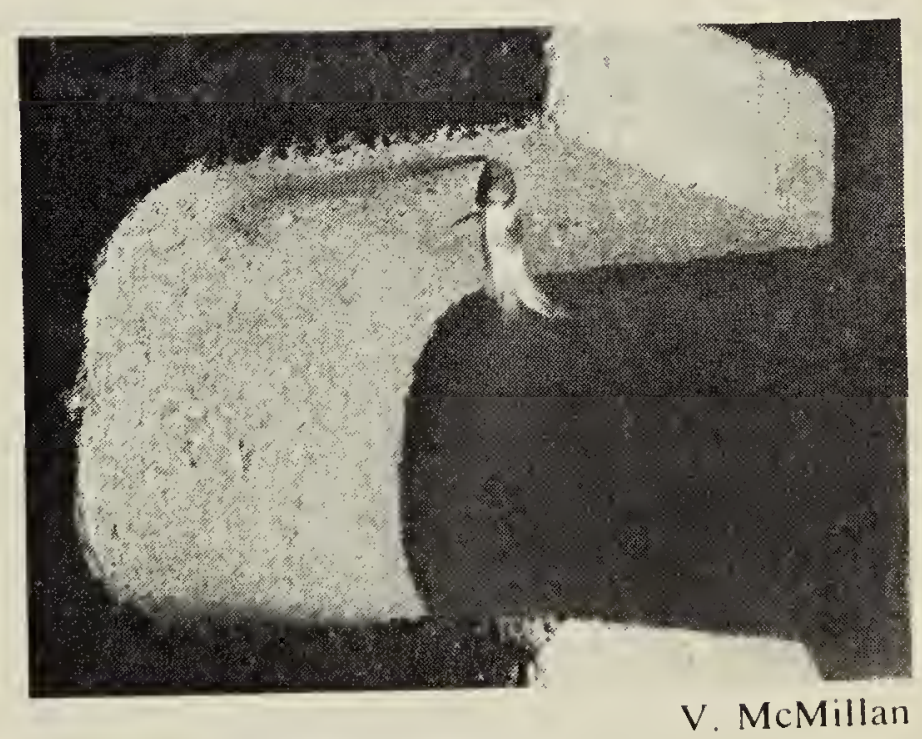

Fig. 4. Nibbling by a strongly banded male defending the cavity of a C-shaped concrete block. 


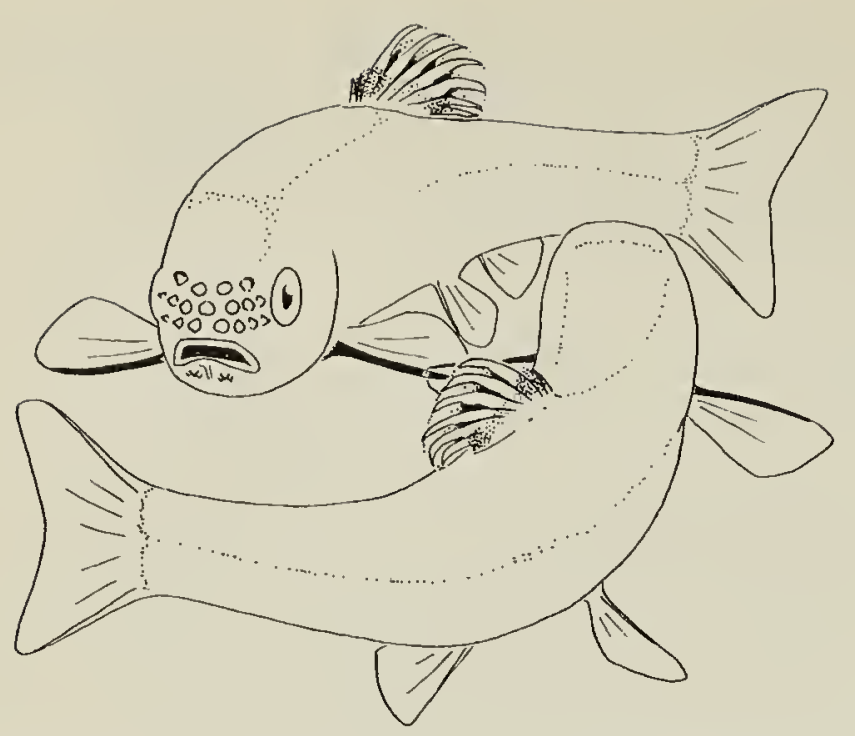

B. McMillan

Fig. 5. Carouseling (circling head-to-tail).

as signaling ownership of the object, attracting mates, and initiating subsequent phases of male reproductive behaviour.

Territory owners also exhibit "nibbling" behaviour, assuming a vertical posture and contacting their object's undersurface with their snout and lips (Fig. 4). Like circling, nibbling may clean the territorial object and advertise the male's presence. During both actions the male's body may be strongly striped.

The appearance of vertical banding also accompanies the expression of intense aggression, as when two males contest a territory. Such fights involve a number of behaviour patterns that, in similar forms, occur in other fish species as well. The two males may charge, chase and bite each ot? They may carousel, circling head tail as each tries to contact the ot (Fig. 5). They may engage in sno butting contests, using their rows pointed tubercles (Fig. 6). Or, one may tailbeat, undulating the poster part of its body so that a current water is directed towards the oppon (Fig. 7). Tailbeating seems to serve intimidating function, operati through the lateral-line sensory syst of the threatened fish.

In aquaria, males may fig vigorously for as long as 30 minut Fish will also butt air stones, sna water beetles (Dytiscus marginali similarly sized fish of other speci and the extended fingers of oberve when these intrude into the territories. D. Isaac, who studi fatheads in a Minnesota lake, report that males carried leeches away fro their territories, and that one mi vigorously battled with a paint turtle.

In most natural situations, howev aggression by territory owners prompt but brief, favoring threats ov prolonged contact with the intrud This is highly advantageous to $t$ species, since disputes can then be se tled quickly and with a minimum physical harm, if any. In fact, even aquaria, where there is no escape fro an aggressor, disputes are resolve without serious damage to either fis And in fathead minnows, as in oth

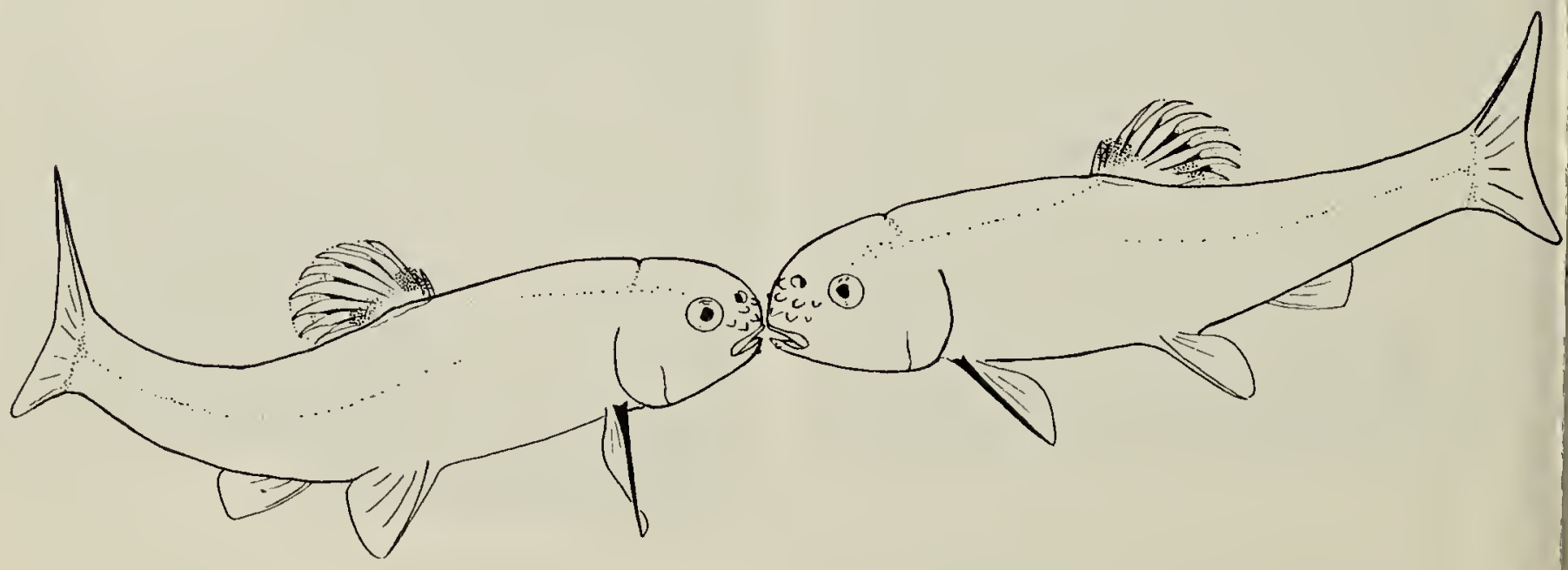

Fig 6. Mutual snout-butting.

B. McMilla 


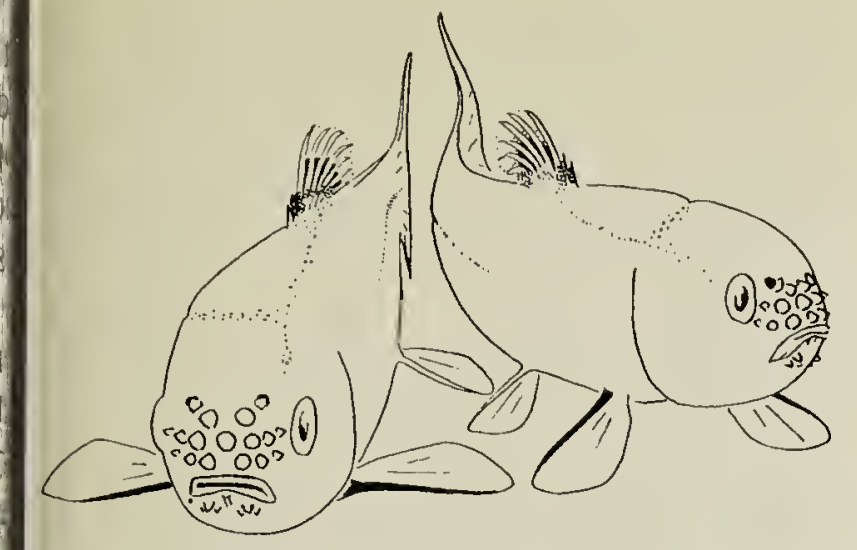

B. McMillan g. 7. Tailbeating. The aggressor, at right, undulates his body, directing a current of water towards the other fish.

erritorial animals, the original owner enerally "wins" each argument over is domain.

An interesting aspect of territorial theads is their strong aggression wards females as well as males. emales, even ripe ones seeking to pawn, are repeatedly butted and hased, although they display little erritorialism or aggression them elves. In some animals, aggressive cts in certain contexts have been lassified as essentially sexual in funcion, since they incite one or both partiers to mate. However, in the case of he fathead, more data are needed pefore we can definitely say that male butting stimulates the female to spawn. For the present, it appears that the nale simply responds to the female as in intruder in his territory; and his iggression is intensified by her requent approaches to the underside of the territorial object - the most heavily guarded site in his domain.

Spawing behaviour, then, is preceded - and punctuated by iumerous attacks on the female. ppawning itself is dependent upon ichieving close lateral contact beween the partners (Fig. 8). Once this s achieved, the fish-with their heads and urogenital areas pressed side to ide - begin to vibrate. Parts of their hacks touch the underside of the erritorial object. The pair may vibrate In one spot for several seconds before releasing eggs and sperm or, more typically, they may circle together helow the object. During this "paired circling" they are often uncoordinated
- one fish may move faster than the other and lateral contact is often broken.

Finally, after a sufficient degree of vibratory stimulation is reached, spawning occurs. Positioning himself beneath the female now, the male pivots her body upwards, pressing her against the undersurface of the territorial object (Fig. 9). In doing so, he particularly uses the posterior part of the body (proportionately longer than the female's) and one of his pectoral fins, whose tubercles probably help maintain contact. The female emits one or perhaps several eggs, which adhere to the undersurface of the object. (They may also fall to the ground.) At approximately the same time the male releases sperm. Then he may resume spawning vibrations. He may also spawn with the same or a different female hours or days later. Once a spawning session is finished, the male chases the female from his territory and rigorously defends the eggs throughout their period of development, which lasts about 5 days. Once hatched however, the fry receive no care.

During the parental phase, site tenacity and territorial aggression are particularly pronounced and a male may remain banded for many hours at a time. The most striking change, however, is in the frequency of circling and nibbling behaviour. Laboratory studies have shown that a male contacts the undersurface of his object

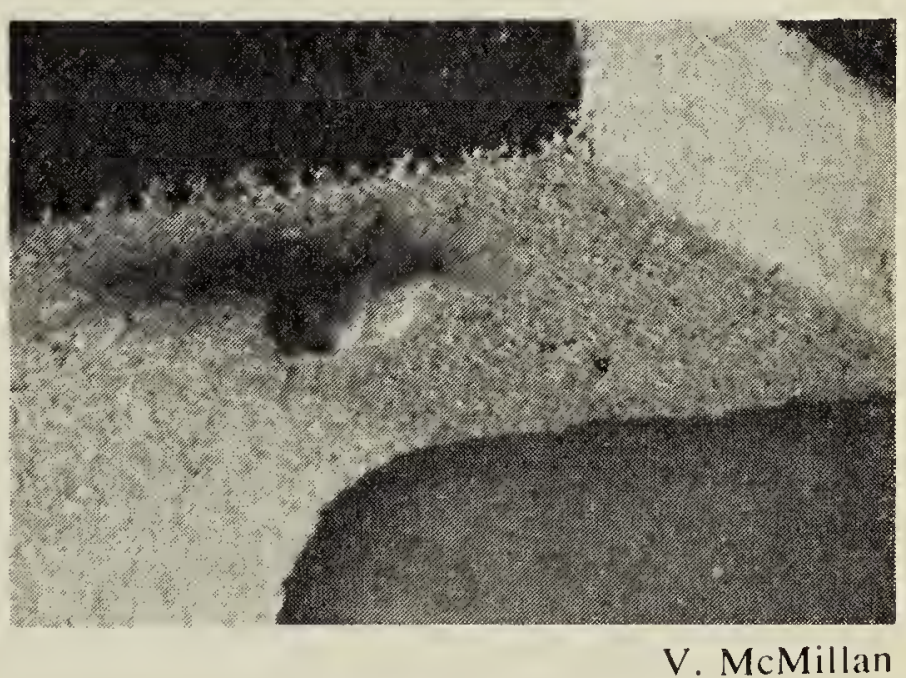

Fig. 8. Paired circling, in which spawning partners circle side-to-side just beneath the spawning surface. The male is on the left. 


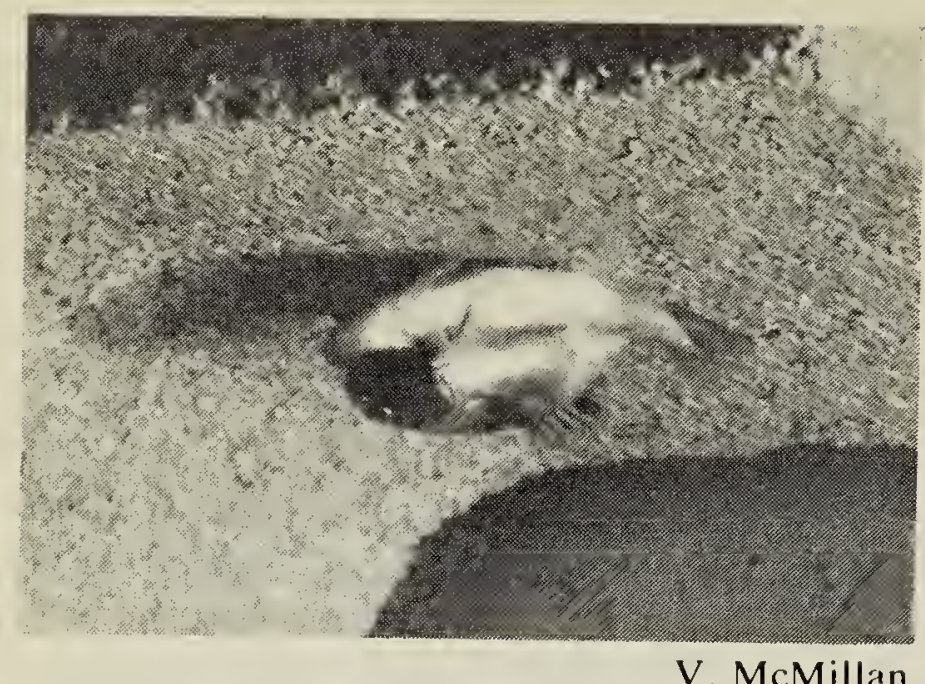

Fig. 9. Pressing of the female against the spawning surface by the male (black head). At this time, egg emission by the female occurs. Already-spawned eggs are visible as diffuse gray blotches on the spawning surface above the female.

with his dorsal pad and lips much more often when eggs are present than when eggs are absent. Evidently spawning or the presence of eggs or both contribute to this impressive change in behaviour.

This change is of great adaptive significance. Frequent circling and nibbling keep the eggs clean and must agitate the water around the eggs, aiding in aeration. This latter function would be especially important in the slow, muddy water occupied by many fathead populations in Saskatchewan. Nibbling also seems to be the mechanism for removing fungused eggs - they are simply eaten and thus prevented from infecting the rest of the batch. Circling may facilitate hatching by sweeping emerging fry free from the egg mass.

Histological studies are clarifying the role of the dorsal pad in parental behaviour. Dr. Smith, at the University of Saskatchewan, Saskatoon, has found that the pad contains a large number of mucus cells, and that circling probably leaves a film of mucus on the eggs. This mucus may help to maintain osmotic balance in the eggs, and may protect them (and the male) from parasites. Its lubricating effect may also prevent egg damage as the batch is rubbed by the male.

The dorsal pad, along with the tubercles, banding and unique behaviour of males, thus fits the adequately for a reproductive style volving strong territoriality and ma parental care. Many questions abo the fathead remain but, fortunate the species is an excellent subject $f$ behaviour studies. Hardy and prolif fatheads tolerate considerable han ling, poor oxygen conditions and e tremes in $\mathrm{pH}$ and salinity. With simp adjustment of temperature at photoperiod, breeding can be induc in aquaria any time of the year. A in clear, shallow waters, usi polaroid sunglasses, one can easily o serve minnows in the field. Thus the are numerous opportunities f naturalists to learn more about $t$ fathead minnow.

Acknowledgements. This article based on a study financed by National Research Council of Canac grant held by Dr. R. J. F. Smith. I a grateful to Dr. Smith for his advic throughout the project, and to $\mathrm{Mr}$. Waddington and Mr. B. McMillan f help in preparing the accompanyir illustrations.

\section{USEFUL REFERENCES}

ISAAC, D. 1961. The ecological life history of fathead minnow, Pimephales promel (Rafinesque). Ph.D. Thesis. Univ. Minn., M neapolis. $150 \mathrm{p}$.

MARKUS, H. C. 1934. Life history of blackhead minnow (Pimephales proneld Copeia 1934: 116-122.

McMILLAN, V. 1972. Mating of the fathead. N Hist. 81(5): $72-78$.

McMILLAN, V. and R. J. F. SMITH. 19 Agonistic and reproductive behaviour of falhead minnow (Pimephales prome Rafinesque). Z. Tierpsychol. In Press.

SMITH, R. J. F. and B. D. MURPHY. 19 Functional morphology of the dorsal pad fathead minnows (Pimephales prome Rafinesque). Trans. Am. Fish. Soc. In Press.

\section{ELEPHANT STEW *}

\section{Medium-size Elephant}

2 Rabbits, optional

Salt and Papper

Cut the elephant into small, bite-si. pieces. Add enough brown gravy to cove Cook over kerosene fire about four wee at 465 degrees. This will serve 3,81 people. If more are expected, two rabb may be added. But do this only emergency; most people do not like hare their stew.

${ }^{*}$ From Conservation News, Nov. 15, 19" 